\title{
The Role of Community Health Workers Within the Continuum of Services for HIV, Viral Hepatitis, and Other STIs Amongst Men Who Have Sex with Men in Europe
}

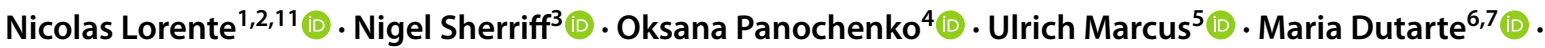

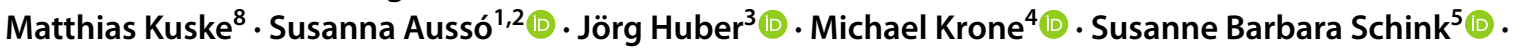 \\ Caoimhe Cawley ${ }^{5}$. Jordi Casabona ${ }^{1,2,9,10}$ (1) Cinta Folch ${ }^{1,2,9}$
}

Published online: 31 July 2020

(c) Springer Science+Business Media, LLC, part of Springer Nature 2020

\begin{abstract}
Little is known about Community Health Workers (CHWs) who work in non-clinical settings to provide sexual health support around HIV, viral hepatitis, and other sexually transmitted infections (STIs) to men who have sex with men (MSM) in Europe and neighbouring countries. This article describes for the first time, who CHWs are, and how they contribute to the continuum of services for HIV, viral hepatitis, and other STIs amongst MSM. The first European Community Health Worker Online Survey (ECHOES) developed in the framework of the EU-funded ESTICOM project (www.esticom.eu), was available in 16 languages (October 2017-January 2018). Amongst the 1035 persons aged 18 and older reporting CHW activities in the previous 12 months, $28.2 \%$ were women, $30.7 \%$ were volunteers, $59.2 \%$ were men self-defining as gay/homosexual, bisexual or queer ('peer CHWs'), and most CHWs worked/volunteered in private not-for-profit organisations (86.4\%). CHWs involvement in the continuum of services for HIV, viral hepatitis and other STIs was as follows: primary prevention (88.6\%), consultation and counselling (58.0\%), testing provision (50.6\%), linkage to care (49.8\%), and treatment and support activities (51.3\%). CHWs were also involved in cross-cutting activities such as developing interventions, advocacy, and engaging in research (46.3\%). CHWs as a public health workforce contribute to all steps of the continuum of services for HIV, viral hepatitis, and other STIs amongst MSM in Europe. National governments should recognise and support CHWs better in order to make their activities more visible and sustainable, and increase their impact on the continuum of services.
\end{abstract}

Keywords Community Health Workers $\cdot$ MSM $\cdot$ HIV $\cdot$ Viral hepatitis $\cdot$ Sexually transmitted infections $\cdot$ Sexual health

\section{Introduction}

Community Health Workers (CHWs), a workforce first described in the 1970s in the US and in low- and middleincome countries, are of growing importance for national health systems, regardless of the level of development of the country [1]. Although it is still difficult to define across countries who they are and what they do, a core characteristic of CHWs is their proximity to the community they serve: they are part of, or have an in-depth understanding of such a community $[2,3]$.

Nicolas Lorente

nlorente@igtp.cat

Extended author information available on the last page of the article
Since 2009, CHWs were recognised formally as a distinctive workforce in the US [4] and have been part of the WHO classification of healthcare workers since 2010 [5]. In Europe, i.e. the European Union (EU) and its neighbouring countries, such formal recognition does not exist.

The 'community' has always been at the heart of the HIV response [6,7], and many studies have shown the efficacy of specific CHW programmes in preventing or managing HIV in different groups and settings [8-12], as well as in contributing to the UNAIDS 90-90-90 targets [13]. However, CHWs have never really been embraced as an integral part of health systems and nationally coordinated HIV responses in Europe. There is still room for full inclusion of community actions in the overall response to the HIV epidemic [14] and more generally in health systems where CHW potential is not fully realised $[15,16]$. 
In Europe, where MSM currently represent approximately $40 \%$ of all new HIV diagnoses [17], many community-based initiatives aiming to reduce the burden of HIV, viral hepatitis, and other sexually transmitted infections (STIs) amongst men who have sex with men (MSM) were reported, especially regarding testing [18-20]. However, the term ' $\mathrm{CHW}$ ' is not commonly used [21] and little is known about the role of CHWs providing sexual health support to MSM.

This article is based on findings from the European Community Health Worker Online Survey (ECHOES) which aimed, for the first time, to assess knowledge, attitudes and practices of CHWs providing sexual health support to MSM in non-clinical settings across Europe. The objective of this article is to describe who these CHWs are, and what they do regarding the continuum of STI services as understood by WHO: preventing, diagnosing, treating and curing [22].

\section{Methods}

ECHOES was implemented in the framework of the European Surveys and Training to Improve MSM Community Health (ESTICOM) project, funded by the European Commission (see details in the funding section). ESTICOM comprised ECHOES, the European MSM Internet Survey (EMIS 2017) [23], and the Training Programme for CHWs providing sexual health support to MSM in non-clinical settings in Europe. The latter was partly based on ECHOES preliminary results, and piloted in 20 European countries. Feedback from the implementation of the Training Programme for CHWs is briefly reported in the discussion of this article.

\section{Study Design and Questionnaire}

In this article, 'Europe' refers to ECHOES eligible countries, i.e. all $28 \mathrm{EU}$ member states and eight neighbouring countries: Bosnia and Herzegovina, Iceland, Moldova, Norway, Russia, Serbia, Switzerland, and Ukraine.

A full description of the ECHOES protocol and questionnaire design has been published elsewhere [24]. In brief, ECHOES was an online survey that aimed to assess knowledge, attitudes and practices of $\mathrm{CHWs}$ providing sexual health support to MSM in Europe. The survey was available in 16 languages and went online in September 2017 for a period of four months. The questionnaire comprised around 175 questions and took approximately $20 \mathrm{~min}$ to complete. The main sections of the questionnaire were as follows: socio-demographics, job, employment status, and organisation worked for; activities as a $\mathrm{CHW}$; populations worked with; barriers to performing CHW activities; recruitment as a $\mathrm{CHW}$; thoughts and feelings about role as a $\mathrm{CHW}$; confidence about one's knowledge; HIV related issues and illicit substance use.

\section{Survey Promotion}

The survey was promoted mainly through direct emailing to Local Multipliers (LMs) identified in all eligible countries. LMs were mainly people working in NGOs offering sexual health support to MSM and assumed to have an extended network amongst CHWs. Promotional material (usually translated into the national language) was sent to LMs with a request for further dissemination. Emails targeted European and national organisations, as well as networks of people working with MSM. The ECHOES launch and updates on recruitment were published on different websites as well as in newsletters and social media (including paid Facebook adverts). One of the biggest challenges was to ensure the target population for the survey understood the term ' $\mathrm{CHW}$ '. Five interviews of $\mathrm{CHWs}$ were thus published to illustrate and improve understanding of who can be considered as $\mathrm{CHW}$ in the framework of ECHOES. A lay article was also published with the same purpose, and other promotional activities were conducted during the course of the survey implementation to increase participation (leaflets and word-clouds posted in social media, online webinar, and marketing at relevant expert meetings and forums like the EU HIV/AIDS, Viral Hepatitis and Tuberculosis Civil Society Forum).

\section{Ethics and Data Protection Issues}

Ethical clearance for the initial questionnaire design and development activities (e.g. piloting) was obtained from the University of Brighton's School of Health Sciences, School Research Ethics and Governance Panel (SREGP, United Kingdom). Additional approval to host the survey online and recruit respondents was received from the Hospital Universitari Germans Trias i Pujol Ethics Committee (Badalona, Spain).

In agreement with the European General Data Protection Regulation (GDPR), an introductory page informed respondents about what kind of data would be collected, storage, protection, treatment, and consent to take part and also to withdraw. Respondents were asked to tick boxes to confirm that they understood each point and agreed to take part in ECHOES. The survey was anonymous: no personal data (e.g. names, addresses), IP addresses, or origin from where participants had been linked to the ECHOES landing page were collected or stored.

\section{Eligibility Criteria and Study Sample}

As ECHOES was the first survey of its kind in Europe, the study population was mostly unknown to the research team. A broad working definition was discussed and agreed by the team and used at the beginning of the online questionnaire 
and in the promotional material to explain who could be considered as a 'CHW':

A community health worker (CHW) is someone who provides sexual health support around HIV/AIDS, viral hepatitis and other sexually transmitted infections, to gay, bisexual and other men who have sex with men. A CHW delivers health promotion or public health activities in community settings (not in a hospital or clinic).

Based on this definition, the eligibility criteria were as follows: providing sexual health support for MSM in a community setting (i.e. not in a hospital or clinic) during the last 12 months, doing so in one of the 36 eligible countries (see above), being aged 18 years or older, and consenting to take part in the survey.

A convenience sample of CHWs was recruited during the 4 months the ECHOES questionnaire was live. Overall, 1181 individuals completed the questionnaire from 25th September 2017 to the 31 st January 2018. Amongst these, 107 respondents were excluded from the final sample because they did not provide sexual health support to MSM in community settings within the previous 12 months. A further 24 respondents were excluded because they were not working in one of the eligible countries, and 15 because they were under 18 years old or did not answer the age question (a technical problem let the first participants continue the questionnaire although they did not provide their age or were under 18 years old, not allowed afterwards). The final study sample $(n=1035)$ is unequally distributed across Europe, with four of the most populous EU countries representing more than half of the sample (Germany, Spain, the UK, and France; $n=546)$, and other countries comprising 1 to 37 respondents (Fig. 1).

\section{Measures and Variables}

The variables described in this article usually report response frequencies for each question item or grouped items, but other key variables required specific processing:

The WHO-5 well-being index is a short self-reported measure of current mental well-being and assesses positive aspects of mental health based on five items: (a) I have felt cheerful and in good spirits, (b) I have felt calm and relaxed, (c) I have felt active and vigorous, (d) I woke up feeling fresh and rested, (e) My daily life has been filled with things that interest me [25]. These items were measured using a 6-point Likert scale (at no time, some of the time, less than half of the time, more than half of the time, most of the time, all of the time). This well-being scale performed well in the ECHOES sample (Cronbach's $\alpha=0.88$, good reliability), and was transformed to a range from 0 to 100 . A score below 50 may indicate that the respondent is at risk for depression [26], the index was thus dichotomised into poor (index $<50$ ) versus good (index $\geq 50$ ) well-being.

The peer role of respondents characterises those men who identified themselves as homosexual, gay, bisexual or queer.

The job title descriptions were gathered using the open question: 'We know that many people do not use the term 'Community Health Worker'. How would you describe your job title?'. Free text answers were first translated into English (705 different answers), and then harmonised for spelling, resulting in a total of 365 different answers. The most frequent ones were reported by $6.7 \%$ of the sample, while $56 \%$ of all answers were mentioned by less than $1 \%$ of the sample. Based on these answers, dummy variables were created using keywords mentioned by more than $1 \%$ of all respondents in order to get more information about

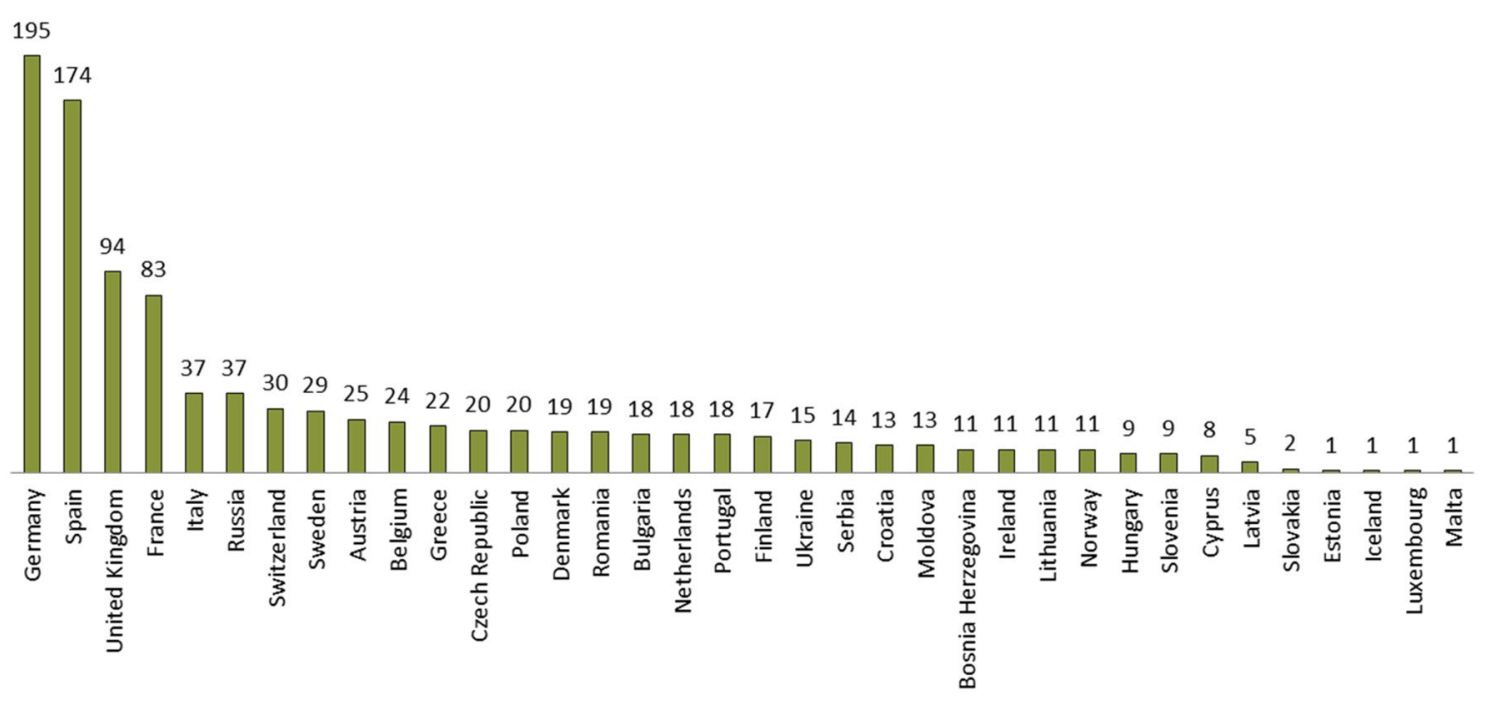

Fig. 1 ECHOES study sample by country respondents work in $(n=1035)$ 
the content of job descriptions. Keywords were single words (e.g. 'volunteer') or the root of a family of words (e.g. 'test*' for 'test', 'testing', 'tester', etc.).

\section{Data Analysis}

A descriptive analysis of respondents' main characteristics (socio-demographics, sexual identity, and health) and their role as CHW (employment, peer role, organisation, job description, and activities) was performed. Frequencies and percentages (excluding missing values) were given both overall and by the country where respondents worked (using chi-squared tests to determine significance of the difference when $\mathrm{p}$-value $<0.05$ ).

Respondents' working countries were grouped using the legal index of Lesbian, Gay, Bisexual, Trans, and Intersex (LGBTI) inequality, or Rainbow-Europe index. The Rainbow-Europe index is made by the European Region of the International Lesbian, Gay, Bisexual, Trans \& Intersex Association (ILGA-Europe, https://rainbow-europe.org/ country-ranking). The index ranges from 0 (gross violations of human rights, discrimination) to 100 (respect of human rights, full equality). The median index of all countries with at least one respondent was 45.7/100. Countries were then grouped as follows: 'low LGBTI inequality countries' for those with an index $>45.7$, 'high LGBTI inequality countries' for those with an index $\leq 45.7$.

This country grouping almost corresponds to the geographical division of the WHO European Region [17], with only Italy and Croatia being classified differently (Fig. 2). Overall, 786 respondents (75.9\%) were from 'low LGBTI inequality countries', and 249 (24.1\%) from 'high LGBTI inequality countries'.

Data management and analysis were performed using SPSS-17 software (SPSS Inc., Chicago, Illinois, USA) and Stata 15 (StataCorp. 2011. Stata Statistical Software: Release 15. College Station, TX, USA).

\section{Results}

\section{Characteristics of CHWs Providing Sexual Health Support to MSM in Non-clinical Settings}

The main characteristics of respondents are depicted in Table 1. CHWs who participated in ECHOES were mostly men $(67.9 \%)$, aged 41 or older $(47.4 \%)$, reported at least 6 years of education after the age of $16(72.2 \%)$, and lived in a city of more than 500,000 inhabitants (56.7\%). Almost half of the sample (44.2\%) indicated that they were living comfortably or very comfortably on their present income, while $15.9 \%$ reported that they were struggling or really struggling on present income. Almost three in five respondents $(58.0 \%)$ identified as gay or homosexual, and one in four $(25.0 \%)$ as heterosexual or straight. Amongst the former, the large majority (92.2\%) reported to be out to more than half, all or almost all their relatives and friends.

CHWs generally felt to be in good or very good health, but more than one in five $(22.3 \%)$ could be considered as
Fig. 2 Country grouping based on the Rainbow-Europe index of LGBTI inequality. "High LGBTI inequality" countries comprise: Bosnia \& Herzegovina, Bulgaria, Cyprus, Czech Republic, Estonia, Hungary, Italy, Latvia, Lithuania, Moldova, Poland, Romania, Russia, Serbia, Slovakia, Slovenia, Ukraine; "Low LGBTI inequality" countries comprise: Austria, Belgium, Croatia, Denmark, Finland, France, Germany, Greece, Iceland, Ireland, Luxembourg, Malta, Netherlands, Norway, Portugal, Spain, Sweden, Switzerland, United Kingdom
Low LGBTI inequality High LGBTI inequality

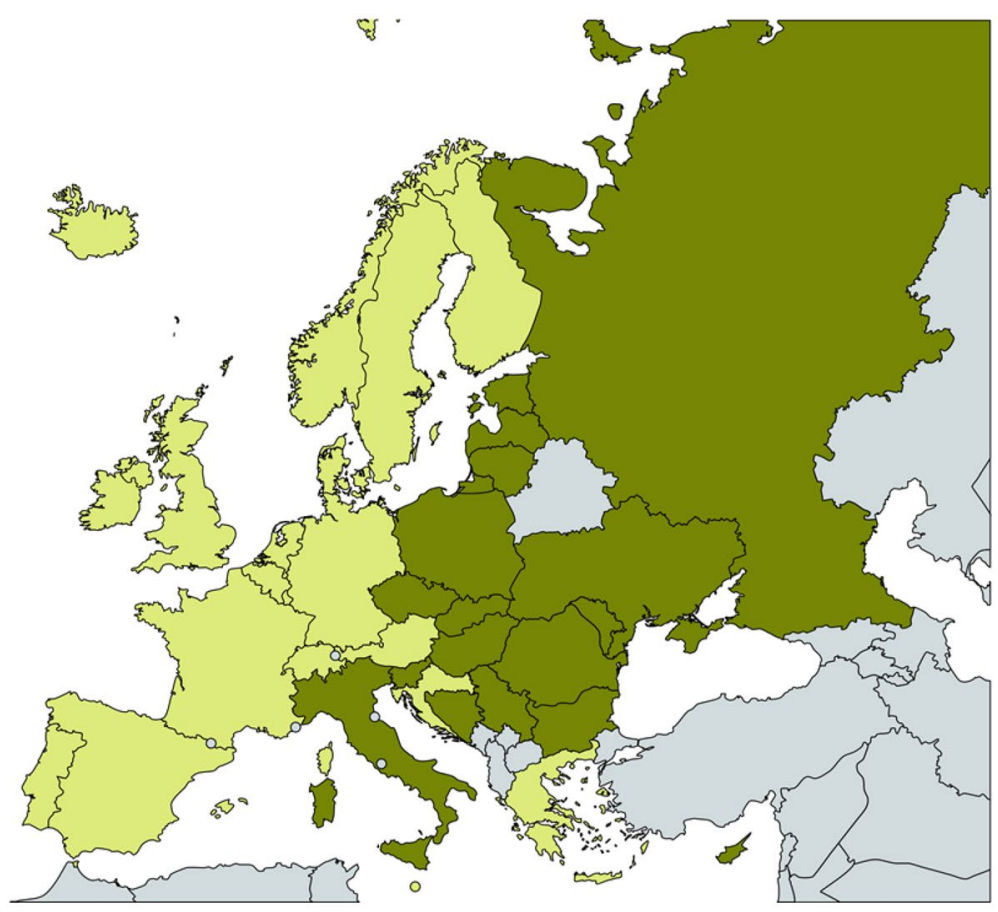


Table 1 Socio-demographic and health-related characteristics of CHWs participating in ECHOES $(n=1035)$

\begin{tabular}{|c|c|c|c|c|c|c|c|}
\hline & \multicolumn{2}{|c|}{$\begin{array}{l}\text { Working } \\
\text { in low } \\
\text { LGBTI } \\
\text { inequality } \\
\text { countries }^{\mathrm{a}} \\
(\mathrm{n}=786) \\
\end{array}$} & \multicolumn{2}{|c|}{$\begin{array}{l}\text { Working } \\
\text { in high } \\
\text { LGBTI } \\
\text { inequality } \\
\text { countries }^{\mathrm{b}} \\
(\mathrm{n}=249) \\
\end{array}$} & \multicolumn{2}{|c|}{$\begin{array}{l}\text { Total } \\
(\mathrm{n}=1035)\end{array}$} & \multirow[t]{2}{*}{$\mathrm{p}$-value } \\
\hline & $\%$ & $\mathrm{n}$ & $\%$ & $\mathrm{n}$ & $\%$ & $\mathrm{n}$ & \\
\hline Age & & & & & & & 0.035 \\
\hline $18-30$ & 19.5 & 153 & 25.7 & 64 & 21.0 & 217 & \\
\hline $31-40$ & 31.0 & 244 & 33.3 & 83 & 31.6 & 327 & \\
\hline 41 or older & 49.5 & 389 & 41.0 & 102 & 47.4 & 491 & \\
\hline Gender & & & & & & & 0.002 \\
\hline Man & 70.2 & 552 & 60.6 & 151 & 67.9 & 703 & \\
\hline Woman & 25.6 & 201 & 36.5 & 91 & 28.2 & 292 & \\
\hline Non binary & 2.7 & 21 & 2.8 & 7 & 2.7 & 28 & \\
\hline Other/prefer not say & 1.5 & 12 & 0 & 0 & 1.2 & 12 & \\
\hline Years in full education since the age of 16 & & & & & & & 0.239 \\
\hline None or 1 year & 3.4 & 26 & 2.5 & 6 & 3.2 & 32 & \\
\hline 2 to 5 years & 25.7 & 198 & 21.1 & 51 & 24.6 & 249 & \\
\hline 6 or more years & 70.9 & 546 & 76.4 & 185 & 72.2 & 731 & \\
\hline Settlement size & & & & & & & 0.782 \\
\hline A village or rural area/A small town—up to 20,000 & 4.1 & 32 & 5.6 & 14 & 4.5 & 46 & \\
\hline A large town or small city—up to 100,000 & 11.2 & 87 & 10.9 & 27 & 11.1 & 114 & \\
\hline A medium-sized city—up to 500,000 & 27.7 & 216 & 27.8 & 69 & 27.7 & 285 & \\
\hline A big city—more than 500,000 & 57.1 & 445 & 55.6 & 138 & 56.7 & 583 & \\
\hline Feelings about present household income & & & & & & & 0.008 \\
\hline Living comfortably or very comfortably on present income & 46.8 & 362 & 36.0 & 89 & 44.2 & 451 & \\
\hline Neither comfortable nor struggling on present income & 38.6 & 299 & 44.1 & 109 & 40.0 & 408 & \\
\hline Struggling or really struggling on present income & 14.6 & 113 & 19.8 & 49 & 15.9 & 162 & \\
\hline Sexual identity & & & & & & & 0.018 \\
\hline Homosexual/gay & 60.6 & 476 & 49.8 & 124 & 58.0 & 600 & \\
\hline Heterosexual/straight & 23.2 & 182 & 30.9 & 77 & 25.0 & 259 & \\
\hline Bisexual & 4.3 & 34 & 6.4 & 16 & 4.8 & 50 & \\
\hline Queer & 4.1 & 32 & 2.8 & 7 & 3.8 & 39 & \\
\hline Lesbian & 1.9 & 15 & 1.2 & 3 & 1.7 & 18 & \\
\hline Any other/do not use a term & 6.0 & 47 & 8.8 & 22 & 6.7 & 69 & \\
\hline Outness $^{c}$ & & & & & & & $<0.001$ \\
\hline More than half, all or almost all relatives and friends & 95.0 & 743 & 83.5 & 207 & 92.2 & 950 & \\
\hline Less than half, few or none & 5.0 & 39 & 16.5 & 41 & 7.8 & 80 & \\
\hline Perceived health status & & & & & & & 0.001 \\
\hline Very good or good & 85.6 & 660 & 76.3 & 184 & 83.4 & 844 & \\
\hline Fair, bad or very bad & 14.4 & 111 & 23.7 & 57 & 16.6 & 168 & \\
\hline WHO-5 well-being scale & & & & & & & 0.180 \\
\hline Poor well-being & 21.3 & 163 & 25.4 & 62 & 22.3 & 225 & \\
\hline Good well-being & 78.7 & 602 & 74.6 & 182 & 77.7 & 784 & \\
\hline Ever tested for HIV & & & & & & & 0.625 \\
\hline No & 6.9 & 53 & 7.8 & 19 & 7.1 & 72 & \\
\hline Yes & 93.1 & 719 & 92.2 & 225 & 92.9 & 944 & \\
\hline Diagnosed with HIV & & & & & & & 0.718 \\
\hline No & 75.0 & 533 & 73.8 & 163 & 74.7 & 696 & \\
\hline Yes & 25.0 & 178 & 26.2 & 58 & 25.3 & 236 & \\
\hline
\end{tabular}

CHW Community Health Worker

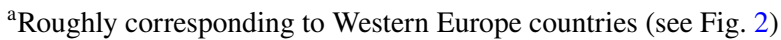

${ }^{b}$ Roughly corresponding to Eastern Europe countries (seeFig. 2)

${ }^{\mathrm{c}}$ Amongst self-identified gays, lesbians, bisexual, or queer respondents

${ }^{\mathrm{d}}$ Amongst those ever tested for HIV. 
having a poor level of well-being according to the WHO-5 well-being index [26]. The majority of respondents (92.9\%) had ever been tested for HIV, and $25.3 \%$ of those ever tested reported to be HIV positive.

Significant differences between CHWs working in countries with low LGBTI inequality (hereafter 'low inequality countries') and CHWs working in countries with high LGBTI inequality (hereafter 'high inequality countries') were observed. CHWs from high inequality countries were younger (25.7\% aged $18-30$ vs. $19.5 \%)$, more often women (36.5\% vs. $25.6 \%$ ), and reported less often living comfortably or very comfortably on their present income $(36.1 \%$ vs. $46.8 \%$ ), or being in good or very good health $(76.3 \%$ vs. $85.6 \%$ ), compared to CHWs from low inequality countries. These latter identified more often as gay/homosexual $(60.6 \%$ vs. $49.8 \%)$ and reported more often being out to more than half, all or almost all their relatives and friends (95.0\% vs. $83.5 \%$ ) compared to CHWs from high inequality countries.

As shown in Table 2, the majority of CHWs who participated in ECHOES reported being paid for this $\mathrm{CHW}$ role
(69.3\%), worked for a private not-for-profit organisation (86.4\%), and were peer CHWs (59.2\%). CHWs from high inequality countries were more often volunteers $(36.5 \%)$ than CHWs from low inequality countries $(28.9 \%)$. Conversely, CHWs from low inequality countries were more often peer CHWs (63.0\%) than those from high inequality countries (47.4\%). Overall, $10.4 \%$ were not trained for their present $\mathrm{CHW}$ role, with no significant difference between CHWs from low and high inequality countries.

Amongst respondents who were not self-employed $(n=975)$, the main reported sources of funding of their organisation were grants from national government or local authority $(79.9 \%)$, charitable or private donation $(61.5 \%)$, fundraising activities (48.2\%), European funding (23.2\%), and fees from services provided (e.g. training, 22\%). Grants from national governments or local authorities were more commonly reported by respondents from low inequality countries $(87.9 \%)$ than by those from high inequality countries (53.4\%), while the latter reported more often that their organisation received European funding $(41.7 \%)$ compared to respondents from low inequality countries (17.6\%).
Table 2 CHW-related characteristics of ECHOES respondents $(\mathrm{n}=1035)$

\begin{tabular}{|c|c|c|c|c|c|c|c|}
\hline & \multicolumn{2}{|c|}{$\begin{array}{l}\text { Working in } \\
\text { low LGBTI } \\
\text { inequality } \\
\text { countries }^{\text {a }} \\
(\mathrm{n}=786)\end{array}$} & \multicolumn{2}{|c|}{$\begin{array}{l}\text { Working } \\
\text { in high } \\
\text { LGBTI } \\
\text { inequality } \\
\text { countries }^{b} \\
(\mathrm{n}=249)\end{array}$} & \multicolumn{2}{|c|}{$\begin{array}{l}\text { Total } \\
(\mathrm{n}=1035)\end{array}$} & \multirow[t]{2}{*}{ P-value } \\
\hline & $\%$ & $\mathrm{n}$ & $\%$ & $\mathrm{n}$ & $\%$ & $\mathrm{n}$ & \\
\hline Employment status as CHW & & & & & & & 0.023 \\
\hline Paid & 71.1 & 556 & 63.5 & 158 & 69.3 & 714 & \\
\hline Volunteer & 28.9 & 226 & 36.5 & 91 & 30.7 & 317 & \\
\hline Peer role & & & & & & & $<0.001$ \\
\hline Peer & 63.0 & 495 & 47.4 & 118 & 59.2 & 613 & \\
\hline Non peer & 37.0 & 291 & 52.6 & 131 & 40.8 & 422 & \\
\hline Training received for the present role of $\mathrm{CHW}$ & & & & & & & 0.887 \\
\hline No & 10.3 & 80 & 10.7 & 26 & 10.4 & 106 & \\
\hline Yes & 89.7 & 694 & 89.3 & 218 & 89.6 & 912 & \\
\hline Organisation worked for & & & & & & & 0.340 \\
\hline Private not-for-profit organisation & 87.3 & 652 & 83.5 & 187 & 86.4 & 839 & \\
\hline Government or other public organisation & 9.8 & 73 & 12.9 & 29 & 10.5 & 102 & \\
\hline Other & 2.9 & 22 & 3.6 & 8 & 3.1 & 30 & \\
\hline Grants from national government or local authorities & 87.9 & 653 & 53.4 & 119 & 79.9 & 772 & $<0.001$ \\
\hline Charitable or private donations & 63.4 & 471 & 55.2 & 123 & 61.5 & 594 & 0.027 \\
\hline Fundraising activities & 49.7 & 369 & 43.5 & 97 & 48.2 & 466 & 0.106 \\
\hline European funding & 17.6 & 131 & 41.7 & 93 & 23.2 & 224 & $<0.001$ \\
\hline Fees from services provided & 24.6 & 183 & 13.5 & 30 & 22.0 & 213 & $<0.001$ \\
\hline
\end{tabular}

CHW Community Health Worker

${ }^{a}$ Roughly corresponding to Western Europe countries (see Fig. 2)

${ }^{b}$ Roughly corresponding to Eastern Europe countries (seeFig. 2)

${ }^{c}$ Amongst respondents who were not self-employed $(n=975)$, multiple answers 
Respondents varied in the way they described their CHW job title; 365 different labels were used after translation into English and minor corrections for harmonisation (see methods section). The most frequently reported job titles were 'volunteer' (6.7\%), 'outreach worker' (5.7\%) and 'sexual

Table 3 Keywords most reported by ECHOES respondents to describe their job title as CHWs $(n=1035$; multiple entries)

\begin{tabular}{|c|c|c|}
\hline & \multicolumn{2}{|l|}{ Total } \\
\hline & \multicolumn{2}{|c|}{$(\mathrm{n}=1035)$} \\
\hline & $\%$ & $\mathrm{n}$ \\
\hline Health $^{* a}$ & 35.5 & 367 \\
\hline $\operatorname{Sex}^{* b}$ & 15.7 & 163 \\
\hline Community & 10.0 & 103 \\
\hline Outreach & 9.6 & 99 \\
\hline Volunteer & 9.5 & 98 \\
\hline Social & 8.2 & 85 \\
\hline Counsellor & 7.9 & 82 \\
\hline Educator & 6.5 & 67 \\
\hline Peer & 4.7 & 49 \\
\hline Consultant & 4.5 & 47 \\
\hline Prevention & 4.4 & 46 \\
\hline Advisor & 4.0 & 41 \\
\hline Psych $^{* c}$ & 3.0 & 31 \\
\hline Nurse & 2.1 & 22 \\
\hline Test $^{* d}$ & 1.4 & 14 \\
\hline
\end{tabular}

*Root used to search for a family of words

ancluding: health, healthcare

${ }^{b}$ Including: sex, sexologist, sexual, chemsex $(n=1)$

${ }^{\mathrm{c}}$ Including: psychiatrist $(\mathrm{n}=1)$, psychological, psychologist, psychology $(n=1)$, psychosocial, psychotherapist

${ }^{\mathrm{d}}$ Including: test, tester, testing health worker' $(5.3 \%)$, but the majority of respondents (56.0\%) provided a label shared by just $1 \%$ or less of the overall sample. 'Community Health Worker' was used by only $2.5 \%$ of the overall sample. When searching for keywords within the labels used, 'health' (35.5\%), and 'sex' (15.7\%) were the most frequent ones in respondents' job title descriptions (Table 3). The most common keywords to describe respondents' CHW job titles could be grouped into 2 categories: (i) the area or domain of action, for instance 'health', 'sex', 'community', 'prevention', 'testing', and/or (ii) the status or function occupied, for instance 'volunteer', 'counsellor', 'educator', 'nurse'.

\section{CHW Activities Regarding the Continuum of Services for HIV, Viral Hepatitis, and Other STIs Amongst MSM}

CHWs were involved in many activities that can be directly related to the different steps of the continuum of services adapted from WHO [22]. Primary prevention is, by far, the most common domain of activity (88.6\%), but all other steps are undertaken by around half of respondents (Fig. 3). Overall, more than one in four respondents $(27.1 \%)$ reported involvement in all the steps of the continuum of services presented here, and almost three in five (58.5\%) reported involvement in 3 or more different steps.

Details of activities related to the continuum of care as well as cross-cutting activities are presented in Table 4. Engagement in primary prevention activities was reported more often by respondents from low inequality countries ( $89.9 \%$ vs. $84.3 \%$ ), while respondents from high inequality countries reported more often being engaged in activities related to consultation and counselling $(65.5 \%$ vs. $55.6 \%)$. No other differences were observed between CHWs from low inequality countries and those from high inequality countries.
Fig. 3 CHW activities targeting men who have sex with men according to the continuum of services for HIV, viral hepatitis, and other STIs $(n=1035)$

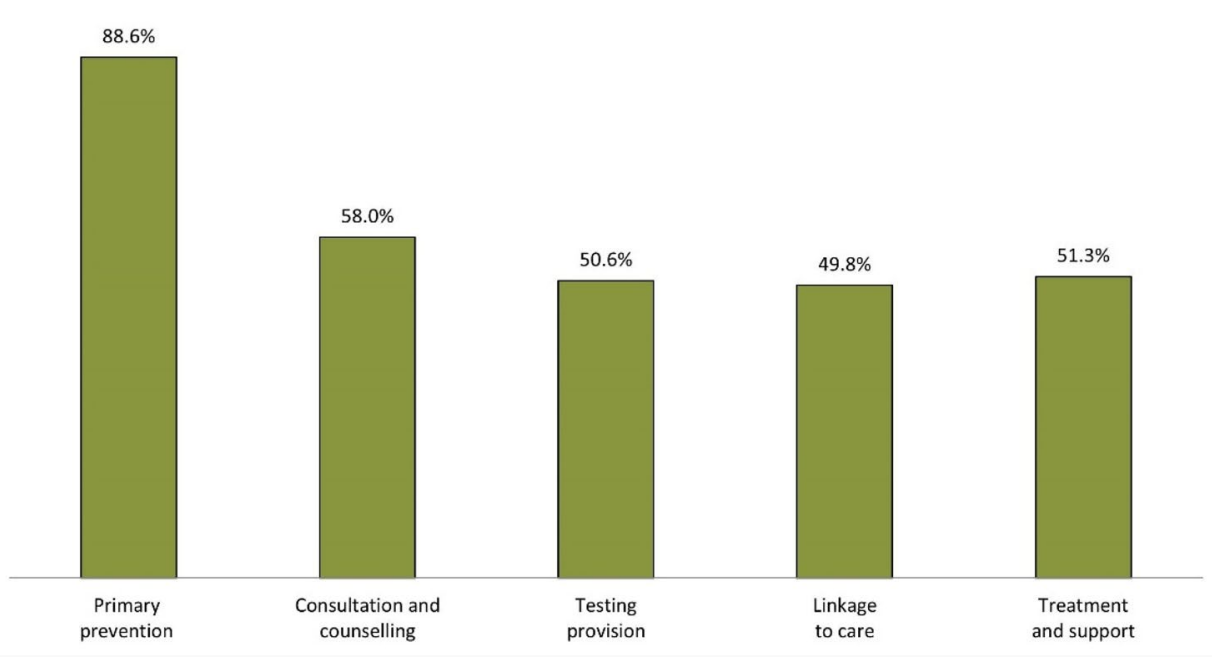


Table 4 ECHOES respondents' main activities $(n=1035)$

\begin{tabular}{|c|c|c|c|c|c|c|c|}
\hline & \multirow{2}{*}{\multicolumn{2}{|c|}{$\begin{array}{l}\text { Working in low } \\
\text { LGBTI inequality } \\
\text { countries }^{\mathrm{a}} \\
(\mathrm{n}=786)\end{array}$}} & \multirow{2}{*}{\multicolumn{2}{|c|}{$\begin{array}{l}\text { Working in high } \\
\text { LGBTI inequality } \\
{\text { countries }{ }^{b}}^{(n=249)}\end{array}$}} & \multicolumn{2}{|l|}{ Total } & \multirow[t]{3}{*}{ p-value } \\
\hline & & & & & \multicolumn{2}{|c|}{$(\mathrm{n}=1035)$} & \\
\hline & $\%$ & $\mathrm{n}$ & $\%$ & $\mathrm{n}$ & $\%$ & $\mathrm{n}$ & \\
\hline Primary prevention & 89.9 & 707 & 84.3 & 210 & 88.6 & 917 & 0.015 \\
\hline Information provision $^{c}$ & 97.6 & 690 & 95.7 & 201 & 97.2 & 891 & 0.149 \\
\hline Interventions ${ }^{\mathrm{c}}$ & 62.8 & 444 & 57.6 & 121 & 61.6 & 565 & 0.175 \\
\hline Consultation and counselling & 55.6 & 437 & 65.5 & 163 & 58.0 & 600 & 0.006 \\
\hline Testing provision & 50.4 & 396 & 51.4 & 128 & 50.6 & 524 & 0.778 \\
\hline Referral and linkage to care & 51.1 & 402 & 45.4 & 113 & 49.8 & 515 & 0.113 \\
\hline Treatment and support activities & 52.2 & 410 & 48.6 & 121 & 51.3 & 531 & 0.326 \\
\hline Information provision $^{\mathrm{d}}$ & 95.9 & 393 & 95.0 & 115 & 95.7 & 508 & 0.700 \\
\hline Interventions $^{\mathrm{d}}$ & 53.9 & 221 & 58.7 & 71 & 55.0 & 292 & 0.354 \\
\hline Cross-cutting activities & 47.8 & 376 & 41.4 & 103 & 46.3 & 479 & 0.074 \\
\hline Developing interventions, outreach and support activities ${ }^{\mathrm{e}}$ & 93.9 & 353 & 89.3 & 92 & 92.9 & 445 & 0.110 \\
\hline Monitoring, evaluation and reporting of organisation's activities ${ }^{\mathrm{e}}$ & 91.2 & 343 & 93.2 & 96 & 91.6 & 439 & 0.520 \\
\hline Advocacy and networking ${ }^{\mathrm{e}}$ & 90.7 & 341 & 89.3 & 92 & 90.4 & 433 & 0.676 \\
\hline Engage with research and or community needs assessments ${ }^{\mathrm{e}}$ & 88.8 & 334 & 92.2 & 95 & 89.6 & 429 & 0.317 \\
\hline Marketing, advertising and media activities ${ }^{\mathrm{e}}$ & 81.6 & 307 & 78.6 & 81 & 81.0 & 388 & 0.490 \\
\hline Staff development ${ }^{\mathrm{e}}$ & 74.5 & 280 & 77.7 & 80 & 75.2 & 360 & 0.505 \\
\hline Management ${ }^{\mathrm{e}}$ & 71.8 & 270 & 78.6 & 81 & 73.3 & 351 & 0.165 \\
\hline Fundraising & 61.7 & 232 & 63.1 & 65 & 62.0 & 297 & 0.795 \\
\hline
\end{tabular}

${ }^{a}$ Roughly corresponding to Western Europe countries (see method section)

${ }^{b}$ Roughly corresponding to Eastern Europe countries, (see method section)

${ }^{c}$ Amongst those reporting engagement in primary prevention activities

${ }^{\mathrm{d}}$ Amongst those reporting engagement in treatment and support activities

${ }^{\mathrm{e}}$ Amongst those reporting engagement in cross-cutting activities

Amongst respondents involved in primary prevention, $97.2 \%$ reported providing information and $61.6 \%$ engaged in prevention interventions (Table 4). 'Vaccinations and preventative medication (e.g. PrEP)' (88.9\%) and 'Chemsex' $(80.2 \%)$ were amongst the main reported topics in terms of information provision, while 'Support using or accessing Pre-Exposure Prophylaxis' (78.7\%) and 'Substance use support' $(51.5 \%)$ were amongst the main reported areas of interventions, in those engaging in prevention activities (data not shown in table).

Amongst respondents involved in treatment and support activities, $95.7 \%$ reported providing information, and $55.0 \%$ engaged in interventions related to treatment (Table 4). 'Mental health support related to treatment' (61.8\%) is one of the main topics reported in terms of information provision, while 'Adherence' (84.3\%) and 'Accompanying users to get treatment' $(65.4 \%)$ were amongst the main reported areas of interventions amongst $\mathrm{CHW}$ s engaging in treatment and support activities (data not shown in table).

Cross-cutting activities, namely strategic and administrative activities that cannot be specifically linked to one step of the continuum of services, were reported by almost half of the sample (46.3\%). Amongst these, 'Developing interventions, outreach and support activities' (92.9\%), 'Monitoring, evaluation and reporting of organisation's activities' (91.6\%), 'Advocacy and networking' (90.4\%), 'Engage with research and or community needs assessments' (89.6\%), and 'Marketing, advertising and media activities' (81.0\%) were the most reported cross-cutting activities. No differences were observed between CHWs from low inequality and CHWs from high inequality countries for these activities (Table 4).

\section{Discussion}

ECHOES is the first ever multi-country survey targeting CHWs who provide sexual health support to MSM in nonclinical settings in Europe. The results of ECHOES afford a first description of this heterogeneous and previously understudied population, including the way they identify 
themselves, and the range and depth of the activities they are involved in.

One of the most important findings of ECHOES is to show the involvement of CHWs in all steps of the continuum of services for HIV, viral hepatitis, and other STIs for MSM in non-clinical settings. Primary prevention is by far the most common activity, but around half of the overall sample engages in each of the other steps of the continuum of services. In that sense, CHWs providing sexual health support to MSM in non-clinical settings are particularly well placed to contribute effectively to UNAIDS 90-90-90 targets [13], or more specifically to reach the 10-10-10, addressing simultaneously individual, social, and structural barriers [27]. However, an investment should be made to address funding issues that threaten the sustainability of CHWs activities. CHWs mostly work in private not-forprofit organisations that are funded by national governments or local authorities, donations, fundraising activities, and European funding. These funds are usually project-based or susceptible to revisions depending on the economic and political context at national or international level.

Beyond their involvement in all steps of the continuum of services for HIV, viral hepatitis, and other STIs, around half of CHWs also engage in cross-cutting activities such as monitoring and evaluation, advocacy, participation in research, and community needs assessments. These activities may be less visible and valued from the public health perspective since they do not impact directly on the main steps of the continuum of services, but are crucial to maintain CHWs' activities (secure funding), and to address MSM needs and the structural barriers MSM face in accessing sexual health services. Participation of CHWs in research or activity monitoring is also essential, both so that researchers may better understand the epidemics and the affected populations, and so that the corresponding populations have the ability to address emerging needs as soon as they come up, and have valid data to advocate for change [28].

Overall, almost one in three CHWs contributes as a volunteer, and although mostly coming from the community they serve (peer $\mathrm{CHWs}$ ), as reported in the wider literature $[2,3]$, a significant proportion of CHWs are women, which is important to bear in mind for future studies among CHWs, but also for organisations looking for CHWs. Female and volunteer CHWs are generally more common in high inequality countries, while paid and peer $\mathrm{CHWs}$ are more common in low inequality countries, which suggests that the socio-political environment limits the willingness and/or ability of MSM to perform CHWs roles and engage as peer CHWs in Eastern Europe. This may also reflect an East/West difference in the emergence and development of HIV/AIDS NGOs. While the first HIV/AIDS NGOs in Western countries were based on activism, often pre-existent to the HIV epidemic, and involving primarily LGBTI people [7, 29], most HIV/AIDS NGOs in Eastern Europe emerged in the post-socialism era of the 1990's, when the ability for such organisations to officially form was just recognised [30].

Most CHWs are in good or very good health, and have good mental well-being. However, one in four CHWs may suffer from depressive symptoms, and CHWs from high inequality countries are less often in good or very good health compared to those from low inequality countries. Special attention to self-care is warranted from CHWs' organisations in order to prevent possible risk of burnout [31], or compassion fatigue [32], and maintain the quality of service provision.

CHWs usually do not use the term 'community health worker', preferring a wide range of nomenclature to describe their job title, as shown in the European scoping review carried out before ECHOES [21]. However, ECHOES and the Training Programme for CHWs (see methods) have opened up the discussion around the concept of CHWs among people working or volunteering with MSM. ECHOES promotion activities and the piloting of the Training Programme made people think about their own contribution as a CHW providing sexual health support to MSM in Europe, and promoted a feeling of being part of a broader, international workforce performing similar tasks and with a common aim, despite the diversity of their roles, jobs titles, backgrounds and cultures.

ECHOES findings should be generalised with caution since the overall sample size is small given the countries' population sizes (though the true size of the CHW population providing sexual health support to MSM is unknown), and the sample is also unequally distributed. To overcome this limitation, respondents were grouped according to the level of the legal index of LGBTI inequality of their country (ILGA-Europe's Rainbow Index). This allowed for comparisons that took differences in levels of inequality towards MSM in different national contexts into account. In addition, as this grouping was fairly congruent with the East/West division of the WHO European region [22], findings can also be interpreted in light of the different cultures and history of these two sub-regions.

Another limitation is the non-inclusion of CHWs working exclusively in clinical settings. This was a methodological choice in order to focus on support and services delivered outside of standard clinical settings. However, many CHWs already work in clinical settings, and clinical staff seem more and more interested in collaborating with CHWs [33]. CHWs working or volunteering in clinical settings should thus be included in the next iteration of ECHOES, in order, for instance, to highlight differences and similarities between those two groups of CHWs.

In conclusion, ECHOES findings emphasise, for the first time in Europe and neighbouring countries, the diversity of profiles and activities of CHWs providing sexual health 
support to MSM, their contribution to all steps of the continuum of services, and their capacity to address MSM's needs as soon as they emerge. A European community of CHWs has come into being, but the real potential of this workforce is still undervalued [14]. CHWs should be acknowledged as a fully-fledged and coherent workforce with its own training and competency framework standards. Political change is needed to support and sustain CHWs activities and formally integrate them in national responses to the epidemics of HIV, viral hepatitis, and other STIs in order to maximise the impact of this workforce.

Acknowledgements The authors want to thank all people who participated in the survey, and those who helped with translation and promotion at the national level. The authors acknowledge the contribution of the participants of the Expert Workshop (from NGOs, academia, public institutes) held in Berlin in April 2018 where preliminary results were presented, as well as all the members of the ESTICOM project consortium, the advisory board, and all those involved in peer reviewing, translating, and otherwise contributing to ECHOES.

Author Contributions NS and JH led the survey conception and questionnaire design, and OP and MK led the survey promotion. Data management and analysis were performed by NL, CF and SA. The first draft of the manuscript was written by NL and all authors commented on previous versions of the manuscript. All authors read and approved the final manuscript.

Funding The European Community Health Worker Online Survey (ECHOES), which formed one of the three major objectives of the European Surveys and Training to Improve MSM Community Health (ESTICOM) project, was implemented under the third European Union Health Programme 2014-2020 in the frame of the service contract 20157101, with the Consumers, Health, Agriculture and Food Executive Agency (Chafea), acting under the mandate from the European Commission (Chafea tender no. Chafea/2015/Health/38).

\section{Compliance with Ethical Standards}

Conflict of interest The authors declare that they have no conflict of interest.

\section{References}

1. Perry, H. B., Zulliger, R., \& Rogers, M. M. (2014). Community health workers in low-, middle-, and high-income countries: An overview of their history, recent evolution, and current effectiveness. Annual Review of Public Health, 35(1), 399-421. https:// doi.org/10.1146/annurev-publhealth-032013-182354.

2. Olaniran, A., Smith, H., Unkels, R., Bar-Zeev, S., \& van den Broek, N. (2017). Who is a community health worker?-A systematic review of definitions. Global Health Action, 10(1), 1272223. https://doi.org/10.1080/16549716.2017.1272223.

3. South, J., Meah, A., Bagnall, A.-M., \& Jones, R. (2013). Dimensions of lay health worker programmes: Results of a scoping study and production of a descriptive framework. Global Health Promotion, 20(1), 5-15. https://doi.org/10.1177/1757975912464248.
4. Mason, T., Wilkinson, G. W., Nannini, A., Martin, C. M., Fox, D. J., \& Hirsch, G. (2011). Winning policy change to promote community health workers: Lessons from Massachusetts in the health reform era. American Journal of Public Health, 101(12), 2211-2216. https://doi.org/10.2105/AJPH.2011.300402.

5. WHO. (2010). Classifying health workers: Mapping occupations to the international standard classification. Geneva: World Health Organization.

6. Gazzard, B. (2014). 30 years of HIV: What have we learned? Journal of the International AIDS Society, 17(4S3), 19478. https ://doi.org/10.7448/IAS.17.4.19478.

7. Wright, J. (2013). Only your calamity: The beginnings of activism by and for people with AIDS. American Journal of Public Health, 103(10), 1788-1798. https://doi.org/10.2105/AJPH.2013.301381.

8. Kenya, S., Chida, N., Symes, S., \& Shor-Posner, G. (2011). Can community health workers improve adherence to highly active antiretroviral therapy in the USA? A review of the literature. HIV Medicine, 12(9), 525-534. https://doi.org/10.111 1/j.1468-1293.2011.00921.x.

9. Sando, D., Geldsetzer, P., Magesa, L., et al. (2014). Evaluation of a community health worker intervention and the World Health Organization's Option B versus Option A to improve antenatal care and PMTCT outcomes in Dar es Salaam, Tanzania: Study protocol for a cluster-randomized controlled health systems implementation trial. Trials, 15(1), 359. https://doi. org/10.1186/1745-6215-15-359.

10. Kerrigan, D., Mbwambo, J., Likindikoki, S., et al. (2019). Project Shikamana: Community empowerment-based combination HIV prevention significantly impacts HIV incidence and care continuum outcomes among female sex workers in Iringa, Tanzania. Journal of Acquired Immune Deficiency Syndromes (1999), 82(2), 141-148. https://doi.org/10.1097/QAI.0000000000002123.

11. Selke, H., Kimaiyo, S., Sidle, J., et al. (2010). Task-shifting of antiretroviral delivery from health care workers to persons living with HIV/AIDS: Clinical outcomes of a community-based program in Kenya. Journal of Acquired Immune Deficiency Syndromes, 55(4), 483-490. https://doi.org/10.1097/QAI.0b013e3181 eb5edb.

12. Lefeuvre, D., Dieng, M., Lamara, F., Raguin, G., \& Michon, C. (2014). Community health workers in HIV/AIDS care. Santé Publique, 26(6), 879-888.

13. Dave, S., Peter, T., Fogarty, C., Karatzas, N., Belinsky, N., \& Pant Pai, N. (2019). Which community-based HIV initiatives are effective in achieving UNAIDS 90-90-90 targets? A systematic review and meta-analysis of evidence (2007-2018). PLOS ONE, 14(7), e0219826. https://doi.org/10.1371/journal.pone.0219826.

14. Collins, C. J., Greenall, M. N., Mallouris, C., \& Smith, S. L. (2016). Time for full inclusion of community actions in the response to AIDS. Journal of the International AIDS Society, 19(1), 20712. https://doi.org/10.7448/IAS.19.1.20712.

15. Hartzler, A. L., Tuzzio, L., Hsu, C., \& Wagner, E. H. (2018). Roles and functions of community health workers in primary care. The Annals of Family Medicine, 16(3), 240-245. https:// doi.org/10.1370/afm.2208.

16. Nickel, S., \& von dem Knesebeck, O. (2019). Effectiveness of community-based health promotion interventions in urban areas: A systematic review. Journal of Community Health. https://doi. org/10.1007/s10900-019-00733-7.

17. ECDC \& WHO. (2019). HIV/AIDS surveillance in Europe 2019. 2018 data (p. 126). Stockholm: European Centre for Disease Prevention and Control (ECDC). Retrieved from May 18, 2020 from https://www.ecdc.europa.eu/sites/default/files/documents/ hiv-surveillance-report-2019.pdf.

18. Croxford, S., Tavoschi, L., Sullivan, A. K., et al. (2019). HIV testing strategies outside of health care settings in the European Union (EU)/European Economic Area (EEA): A systematic 
review to inform European Centre for Disease Prevention and Control guidance. HIV Medicine, 21(3), 142-162. https://doi. org/10.1111/hiv.12807.

19. Fernàndez-López, L., Reyes-Urueña, J., Agustí, C., et al. (2016). The COBATEST network: A platform to perform monitoring and evaluation of HIV community-based testing practices in Europe and conduct operational research. AIDS Care, 28(Suppl 1), 32-36. https://doi.org/10.1080/09540121.2016.1146218.

20. Meulbroek, M., Ditzel, E., Saz, J., et al. (2013). BCN Checkpoint, a community-based centre for men who have sex with men in Barcelona, Catalonia, Spain, shows high efficiency in HIV detection and linkage to care. HIV Medicine, 14(Suppl 3), 25-28. https:// doi.org/10.1111/hiv.12054.

21. Folch, C., Fernández-Dávila, P., Palacio-Vieira, J., Dutarte, M., Corbelli, G. M., \& Block, K. (2017). A Review of Community Health Worker (CHW) knowledge, attitudes and practices relating to the sexual health of MSM, including existing training materials and manuals in Europe and neighbouring countries (D5.1) (p. 178). Luxembourg: European commission. Retrieved from May 18, 2020 from https://www.esticom.eu/Webs/ESTICOM/EN/ echoes/chw-review/D5_1_Review_CHW_KAP_MSM_Healt h.pdf.

22. WHO. (2016). Global health sector strategy on sexually transmitted infections 2016-2021: Towards ending STIs (p. 61). Geneva: World Health Organization. Retrieved from May 18, 2020 https ://apps.who.int/iris/bitstream/handle/10665/246296/WHO-RHR16.09-eng.pdf.

23. Weatherburn, P., Hickson, F., Reid, D. S., Marcus, U., \& Schmidt, A. J. (2019). European Men-Who-Have-Sex-With-Men Internet Survey (EMIS-2017): Design and methods. Sexuality Research and Social Policy. https://doi.org/10.1007/s13178-019-00413-0.

24. Sherriff, N., Huber, J., McGlynn, N., et al. (2020). Nonclinical sexual health support for HIV, viral hepatitis, and other sexually transmitted infections in gay, bisexual, and other men who have sex with men: Protocol for a European Community Health Worker Online Survey (ECHOES). JMIR Research Protocols, 9(2), e15012. https://doi.org/10.2196/15012.

25. Topp, C. W., Østergaard, S. D., Søndergaard, S., \& Bech, P. (2015). The WHO-5 well-being index: A systematic review of the literature. Psychotherapy and Psychosomatics, 84(3), 167-176. https://doi.org/10.1159/000376585.
26. Becha, P., \& Pichot, P. (1994). Rating scales for psychopathology, health status and quality of life. Compendium on documentation in accordance with the DSM-m-r and WHO systems. Nordic Journal of Psychiatry, 48(4), 300-301. https://doi.org/10.3109/08039 489409078153.

27. Vincent, W., Sevelius, J., Lippman, S. A., Linnemayr, S., \& Arnold, E. A. (2019). Identifying opportunities for collaboration across the social sciences to reach the 10-10-10: A multilevel approach. JAIDS Journal of Acquired Immune Deficiency Syndromes, 82, S118. https://doi.org/10.1097/QAI.000000000000217 0 .

28. Ahmed, S. M., \& Palermo, A.-G. S. (2010). Community engagement in research: Frameworks for education and peer review. American Journal of Public Health, 100(8), 1380-1387. https:// doi.org/10.2105/AJPH.2009.178137.

29. Coates, T. J. (2008). What is to be done? AIDS (London, England), 22(9), 1079-1080. https://doi.org/10.1097/QAD.0b013 e3282f8afb0.

30. Owczarzak, J. (2010). Activism, NGOs, and HIV prevention in postsocialist Poland: The role of "Anti-Politics". Human Organization, 69(2), 200-211.

31. Shumba, S. (2016). Causes of burnout: Lessons from Non Governmental Organisations responding to emergencies in the Midlands Region of Zimbabwe. IOSR Journal of Humanities And Social Science, 21(6), 14-21. https://doi.org/10.9790/0837-2106081421.

32. Figley, C. R. (2002). Compassion fatigue: Psychotherapists' chronic lack of self care. Journal of Clinical Psychology, 58(11), 1433-1441. https://doi.org/10.1002/jclp.10090.

33. Chaidez, V., Palmer-Wackerly, A. L., \& Trout, K. E. (2018). Community health worker employer survey: Perspectives on CHW workforce development in the Midwest. Journal of Community Health, 43(6), 1145-1154. https://doi.org/10.1007/s1090 0-018-0533-x.

Publisher's Note Springer Nature remains neutral with regard to jurisdictional claims in published maps and institutional affiliations.

\section{Affiliations}

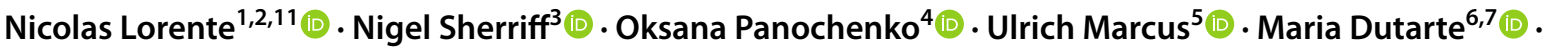

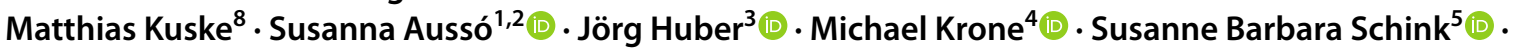 Caoimhe Cawley ${ }^{5}$. Jordi Casabona ${ }^{1,2,9,10}$ (Cinta Folch ${ }^{1,2,9}$}

Nigel Sherriff

N.S.Sherriff@brighton.ac.uk

Oksana Panochenko

Oksana.Panochenko@aidsactioneurope.org

Ulrich Marcus

MarcusU@rki.de

Maria Dutarte

dutarte@hotmail.com

Matthias Kuske

matthias.kuske@dah.aidshilfe.de

Susanna Aussó

susanna.ausso@gmail.com
Jörg Huber

J.Huber@brighton.ac.uk

Michael Krone

Michael.Krone@aidsactioneurope.org

Susanne Barbara Schink

SchinkS@rki.de

Caoimhe Cawley

caoimhecawley@gmail.com

Jordi Casabona

jcasabona@iconcologia.net

Cinta Folch

cfolch@iconcologia.net 
1 Centre Estudis Epidemiològics Sobre Les Infeccions de Transmissió Sexual I Sida de Catalunya (CEEISCAT), Agència de Salut Pública de Catalunya, 08916 Badalona (Barcelona), Spain

2 Institut Investigació Germans Trias I Pujol (IGTP), 08916 Badalona (Barcelona), Spain

3 School of Health Sciences, and Centre for Transforming Sexuality \& Gender, University of Brighton, Brighton BN1 9PH, UK

4 AIDS Action Europe (AAE), 10963 Berlin, Germany

5 Robert Koch Institute, 13353 Berlin, Germany

6 European AIDS Treatment Group (EATG), 1000 Brussels, Belgium
7 European Patients' Forum (EPF), 1040 Brussels, Belgium

8 Deutsche Aidshilfe, 10963 Berlin, Germany

9 CIBER Epidemiologia y Salud Pública (CIBERESP), 28029 Madrid, Spain

10 Departament de Pediatria, Obstetrícia i Ginecologia i de Medicina Preventiva, Universitat Autònoma de Barcelona, 08916 Badalona (Barcelona), Spain

11 Centre D'Estudis Epidemiològics Sobre Les ITS I Sida de Catalunya (CEEISCAT), Fundació Institut D'Investigació en Ciències de La Salut Germans Trias I Pujol (IGTP), Edifici Muntanya, Carretera de Can Ruti, Camí de les Escoles s/n, 08916 Badalona, Barcelona, Spain 